\title{
In Vitro Assessment of Antifungal Caspofungin on Leishmania donovani Culture Isolation
}

\author{
Narayan Raj Bhattarai, ${ }^{1}$ Keshav Rai, ${ }^{1}$ Suman Rijal, ${ }^{2}$ and Basudha Khanal ${ }^{1}$ \\ ${ }^{1}$ Department of Microbiology, B. P. Koirala Institute of Health Sciences, Dharan, Nepal \\ ${ }^{2}$ Department of Internal Medicine, B. P. Koirala Institute of Health Sciences, Dharan, Nepal \\ Correspondence should be addressed to Narayan Raj Bhattarai; bhattarai03@yahoo.com
}

Received 18 July 2017; Revised 8 November 2017; Accepted 15 November 2017; Published 17 December 2017

Academic Editor: José Ramón Blanco

Copyright (C) 2017 Narayan Raj Bhattarai et al. This is an open access article distributed under the Creative Commons Attribution License, which permits unrestricted use, distribution, and reproduction in any medium, provided the original work is properly cited.

\begin{abstract}
Leishmania parasite isolation from the human aspirates is always challenging due to most probability of the fungal contamination and the use of antifungal drug which could support the selective growth of the Leishmania parasite. In this study, we examine the effect of antifungal drug caspofungin on the promastigote stage of Leishmania donovani. Promastigote parasite was cultivated in M199 + 20\% heat-inactivated fetal calf serum and plated in 96-well plates. Seven different concentrations of caspofungin $(512 \mu \mathrm{g} / \mathrm{ml}$ to $8 \mu \mathrm{g} / \mathrm{ml})$ were exposed to parasites, and 50\% inhibitory concentration $\left(\mathrm{IC}_{50}\right)$ was calculated. Candida spp. was used in the experiments to know the efficacy of caspofungin to inhibit fungal growth. The $\mathrm{IC}_{50}$ values of Leishmania strains ranged from 23.02 to $155.80 \mu \mathrm{g} / \mathrm{ml}$ (mean $90.25 \pm 39.01 \mu \mathrm{g} / \mathrm{ml}$ ), and it was significantly higher $(P$ value $=0.02)$ than $\mathrm{IC}_{50}$ values of Candida spp. (ranged from 0.001 to $0.12 \mu \mathrm{g} / \mathrm{ml}$, mean $=0.05 \pm 0.05 \mu \mathrm{g} / \mathrm{ml}$ ). The reduced growth rate of the parasite was found with exposure to $50 \mu \mathrm{g} / \mathrm{ml}$ of caspofungin. Growth inhibition of Leishmania donovani is significantly lower with caspofungin and could be used to protect the parasite cultivation from fungal contamination.
\end{abstract}

\section{Background}

Leishmania parasite cultivation in routine diagnostic and research laboratories is facing a major problem of microbial contamination despite strict adherence on aseptic microbiological practices. In general, the common antibiotics like penicillin and streptomycin are frequently used to prevent the bacterial contamination, but in particular these drugs have also limited a spectrum of inhibition to rule out the possibility of contamination. In contrary, fungal contamination during the parasite cultivation is another challenging arm in most of the laboratories. Yeast and yeast-like organisms are always reported as a major source of contamination during parasite culture. In fact, the antifungal compounds are rarely used to prevent fungal contamination in parasite culture. Recently, the report of cell banks showed that $39 \%$ of specimens are contaminated over a 2 -year period and fungi were identified in $8 \%$ of these [1]. Polyene macrolide drugs (amphotericin and nystatin) have been used to reduce fungal contamination in cell line cultures $[2,3]$, and they target ergosterol in the fungal cell membrane. Lipid composition in Leishmania parasite cell membrane is similar that in fungi and yeast [4]. These drugs have also been shown to interact with Toll-like receptors and CD14 to induce signal transduction and release of inflammatory cytokines [5]. Hence, these drugs significantly affect parasite's cell physiology that can disrupt parasite cell cycle. Knowing the fact of antifungal antibiotics that are also potential inhibitors to the parasite growth itself, the exploration of antifungal compound which is not inhibiting the parasite growth could prevent the fungal contamination.

Caspofungin, an echinocandin drug, is used clinically for the invasive fungal disease. It kills the fungi by inhibiting 1-3- $\beta$-D-glucan synthesis in fungal cell wall [6]. It has been reported that caspofungin can effectively inhibit several contaminating clinical isolates of Apergillus spp., Penicillium, etc. [7]. The mammalian cell lines have found high resistance towards caspofungin [8]. The cells of Leishmania 
parasite are more similar to the mammalian cells. Therefore, the current study has an aim to determine the effect of caspofungin on Leishmania parasite as a proof of principle for their application in the culture of Leishmania parasite in order to avoid fungal contamination.

\section{Materials and Methods}

2.1. Parasite Promastigote Cultivation. The clinical isolates of L. donovani were isolated from the bone marrow of visceral leishmaniasis patients using the Tobie's agar with Locke's overlay. Later on, the culture was transferred to M199 with $20 \%$ fetal calf serum and cryopreserved at $-80^{\circ} \mathrm{C}$ with $10 \%$ glycerol. The parasite was taken out of cryobank and M199 (Sigma-Aldrich, Cat. No. 2520), supplemented with $20 \%$ heat-inactivated fetal calf serum (Invitrogen), and was used to maintain promastigote parasite. $5 \times 10^{5}$ parasite $\mathrm{per} / \mathrm{ml}$ was inoculated in final $5 \mathrm{ml}$ medium and incubated at $26^{\circ} \mathrm{C}$ [9]. The growth curve of the parasite was maintained for a week to determine the parasite growth rate. The Leishmania species isolates were determined by using the PCR assays targeting L. donovani(donovani) specific ribosomal DNA and followed by the PCR-RFLP heat shock protein 70 .

2.2. Fungi Cultivation. Candida spp. was isolated from the clinical specimen at BPKIHS by Sabouraud dextrose agar (SDA). Candida species was confirmed by using germ tube test, sugar fermentation, growth at $45^{\circ} \mathrm{C}$ on SDA broth, and assimilation tests with xylose and $\alpha$-methyl-D-glucoside. It was transferred to M199 with 20\% heat-inactivated fetal calf serum (invitrogen) with $5 \times 10^{5}$ parasite $\mathrm{per} / \mathrm{ml}$ and then incubated at $26^{\circ} \mathrm{C}$ [10]. The growth rate of Candida was determined by maintaining the growth curve for a week.

2.3. Preparation of Drug. $50 \mathrm{mg}$ of caspofungin (Merck, USA) was dissolved in $5 \mathrm{ml}$ sterile distilled water $(10 \mathrm{mg} / \mathrm{ml})$ and mixed thoroughly for 5 minutes. The drug solution was sterilized through a filter of pore size $0.2 \mu \mathrm{m}$ (PVDF), and drug solution was preserved at $-80^{\circ} \mathrm{C}$.

\subsection{Drug Inhibition Measurement}

2.4.1. Leishmania Parasite. Log-phase promastigote parasites from third day of subculture were centrifuged at $3200 \mathrm{rpm}$ for 10 minutes; parasites were counted and diluted to make $10^{6}$ parasite $/ \mathrm{ml}$. $100 \mu \mathrm{l}$ of parasites was plated out in duplicate on sterile 96-well plates (Corning Costar, USA, Cat. No. CLS3596). Each well was topped with $100 \mu \mathrm{l}$ of seven different concentrations of caspofungin ranging from $512 \mu \mathrm{g} / \mathrm{ml}$ to $8 \mu \mathrm{g} / \mathrm{ml}$, including one negative control. The $96-$ well plates were covered with a sealing tape and incubated at $26^{\circ} \mathrm{C}$ for 4 days. Finally, viable parasites after exposure to caspofungin were determined by the trypan blue assay.

2.4.2. Candida spp. Day 2 subculture of Candida was centrifuged at $3200 \mathrm{rpm}$ for 10 minutes and resuspended to final cell density $10^{6}$ cells $/ \mathrm{ml} .100 \mu \mathrm{l}$ of Candida was transferred to duplicate wells of 96-well plates. Each well was topped with $100 \mu \mathrm{l}$ of seven different concentrations of caspofungin ranging from $8 \mu \mathrm{g} / \mathrm{ml}$ to $0.00051 \mu \mathrm{g} / \mathrm{ml}$. The $96-$ well plates were covered with a sealing tape and incubated at $26^{\circ} \mathrm{C}$ for 3 days. Then, viable fungal cells after exposure to caspofungin were determined by the trypan blue assay.

2.5. Trypan Blue Viable Count Assay. The viable cells were counted in each well using the trypan blue $(0.2 \%)$ dye exclusion method, where viable parasite became colourless and dead cells appear blue [11].

2.6. Calculation of $I_{50}$. Viable count of each well was entered in Microsoft Excel 2007, and log transformation was made for each drug concentration. These values were transferred in a GraphPad Prism version 5, and $\mathrm{IC}_{50}$ values were analysed for each strain using sigmoidal dose-response model (nonlinear regression) for caspofungin assay [12].

\section{Statistical Analysis}

All data were subjected to statistical analysis using Graphpad Prism Version 5. $P$ values were calculated by Student's $t$-test or analysis of variance depending on the data. $P$ values of less than 0.05 were considered as significant.

\section{Results}

The two Leishmania strains BPK206/0 cl10 and BPK632/0 were tested to determine $\mathrm{IC}_{50}$ against caspofungin, and detailed results were presented in Table 1 . The $\mathrm{IC}_{50}$ values of Leishmania strains ranged from 23.02 to $155.80 \mu \mathrm{g} / \mathrm{ml}$ (mean $=90.25 \pm 39.01$ ), as shown in Table 1 . The parasite growth curve was also maintained with different concentrations of caspofungin $(10 \mu \mathrm{g} / \mathrm{ml}, 25 \mu \mathrm{g} / \mathrm{ml}$, and $50 \mu \mathrm{g} / \mathrm{ml})$ along with control. Caspofungin concentration more than $25 \mu \mathrm{g} / \mathrm{ml}$ significantly inhibits the parasite growth than others, as shown in Figure 1.

$\mathrm{IC}_{50}$ values of Candida spp. were ranged from 0.001 to $0.12 \mu \mathrm{g} / \mathrm{ml}$ (Table 1). The $\mathrm{IC}_{50}$ of Candida is significantly lower than Leishmania strains $(P$ value $=0.02)$.

\section{Discussion}

In vitro cultivation of slow-growing pathogenic protozoan parasites is a difficult process as compared to bacterial and fungal culture. In fact, the longer generation time and requirement of complex nutrients are the main reasons for slow growth in parasite culture. Hence, it requires to maintain an extensive aseptic procedure during the primary isolation and culture maintenance in order to avoid contamination. However, abundant numbers of viable organisms are essentially required not only for confirmatory diagnosis but also for several downstream applications and drug susceptibility assay. Among others, L. donovani was most commonly cultivated in modified Tobie's blood agar at different tropics, but it was most commonly observed with 
TABLE 1: $\mathrm{IC}_{50}$ of strains tested with caspofungin.

\begin{tabular}{lcc}
\hline Strain & $\mathrm{IC}_{50} \mu \mathrm{g} / \mathrm{ml}($ mean $\pm \mathrm{SD})$ & Range $(\mu \mathrm{g} / \mathrm{ml})$ \\
\hline BPK206/0 cl10 & $61.70 \pm 35.97$ & 23.02 to 121.90 \\
BPK632/0 & $118.8 \pm 3.25$ & 46.87 to 155.80 \\
Candida spp. & $0.05 \pm 0.07$ & 0.001 to 0.12 \\
\hline
\end{tabular}

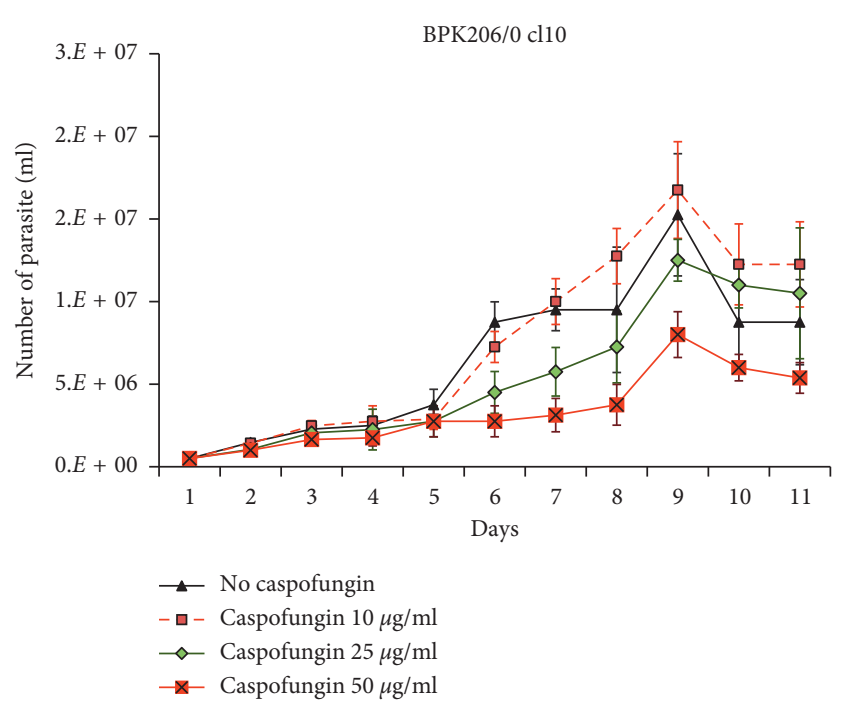

(a)

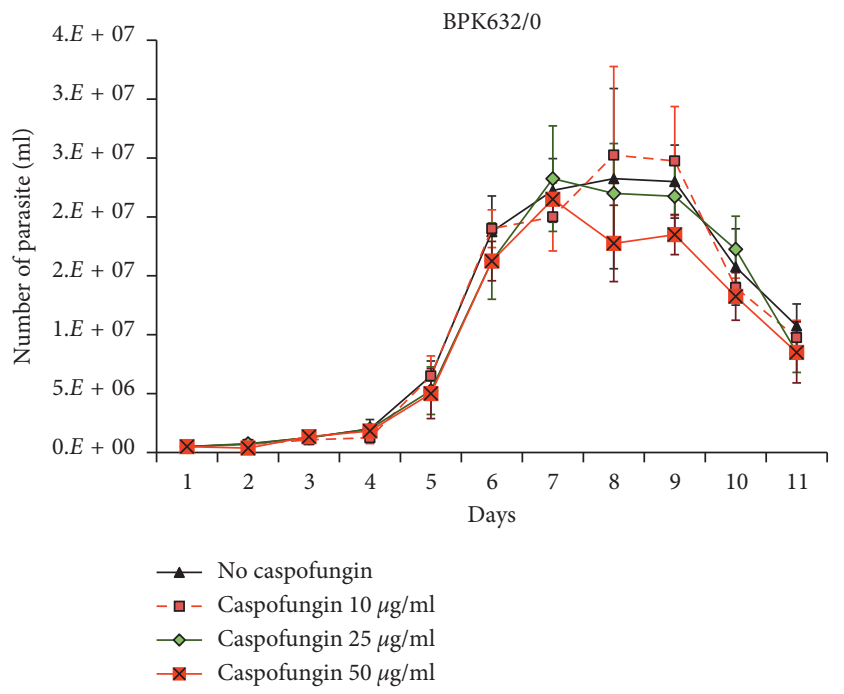

(b)

FIgURE 1: Growth curve of Leishmania parasite with different concentrations of caspofungin. Error bar indicates the 95\% confidence interval of the mean based on triplicate culture of different strains. (a) BPK206/0 cl10 growth curve. (b) BPK632/0 growth curve.

yeast-like contamination during the isolation and maintenance of the parasite. The contamination in parasite culture could be due to the humid environmental condition to support rapid growth of yeast in the different endemic zones. Moreover, the lack of well-equipped laboratory facility to process the clinical specimen for in vitro culture would be another factor for the contamination. Therefore, there is requirement of certain antifungal agents which have no inhibitory effect to the $L$. donovani culture and also protect from the fungal contamination. That is why we undertook to assess the inhibitory effect of antifungal drugs in L. donovani during the parasite cultivation.

Our experimental results showed that L. donovani had significantly higher $\mathrm{IC}_{50}$ to caspofungin than Candida spp. which indicates that the Leishmania parasite had higher tolerance properties to caspofungin. Both Leishmania and Candida cells are eukaryotic in nature, but the Candida cell contains the cell wall but Leishmania lacks the cell wall. In Candida, the enzyme 1-3- $\beta$-D-glucan synthase in cell membrane has essential roles in cell wall formation. Since the caspofungin has a potential power to inhibit the function of 1-3- $\beta$-D-glucan synthase, it inhibits the growth of Candida. Therefore, the least growth inhibition was found in $L$. donovani isolates due to the lack of 1-3- $\beta$-D-glucan synthase. In addition, the growth curve of Leishmania culture isolates was also assessed in the presence of three different caspofungin concentrations $(10 \mu \mathrm{g} / \mathrm{ml}, 25 \mu \mathrm{g} / \mathrm{ml}$, and $50 \mu \mathrm{g} / \mathrm{ml}$ ). It showed that $50 \mu \mathrm{g} / \mathrm{ml}$ caspofungin could inhibit a few strains of Leishmania, and no inhibition was determined in less than $50 \mu \mathrm{g} / \mathrm{ml}$ of caspofungin. In contrast, Candida growth was inhibited with lesser concentration of caspofungin, and no growth was observed in culture incorporated with $10 \mu \mathrm{g} / \mathrm{ml}$ caspofungin. Moreover, Leishmania parasite growth can adapt in five times more concentration of caspofungin than the Candida spp. We found that it could be advantageous to Leishmania culture procedure in order to prevent fungal contamination since Leishmania parasite growth can tolerate $25 \mu \mathrm{g} / \mathrm{ml}$ concentration of caspofungin. Hence, $25 \mu \mathrm{g} / \mathrm{ml}$ caspofungin concentration could be useful to overcome the fungal contamination in Leishmania culture although further study with large sample is required.

Leishmania parasites have digenetic life stage, and they are transforming from nonmotile amastigote to motile promastigote stage during in vitro isolation of the parasite from clinical specimens [9]. Caspofungin must not inhibit the parasite promastigote transformation from the beginning of isolation attempts in order to use against the fungal contamination since the Leishmania promastigote transformation might be inhibited by a few antibiotics [13]. The efficacy on the development of Leishmania promastigote in the presence of caspofungin was also examined. But, there was no significant reduction in the development of promastigote in parasite culture from clinical specimen (data not shown). Furthermore, Leishmania cell morphology in viable cultures was examined by phase-contrast microscopy, and promastigote cell morphology was not significantly different with/without caspofungin. This evidence indicates that the Leishmania parasite promastigote development was not negatively affected by the caspofungin.

However, there could be a question of efficacy of the drug towards other fungal contaminations rather than Candida. Undoubtedly, it could also inhibit the growth of all fungi since the key enzyme $1-3-\beta$-D-glucan synthase is essential for the cell wall formation in all fungus and yeast. The fungal growth inhibition of Apergillus spp. and Penicillium spp. [7] was already reported in other than Candida spp. In 
conclusion, in this study, we show that caspofungin could be the potential agent for the selective growth of $L$. donovani culture isolation since it has no inhibitory effect towards the concentration in which the fungal cell viability is terminated.

\section{Conflicts of Interest}

The authors declare that they have no conflicts of interest.

\section{Acknowledgments}

The authors would like to acknowledge Mr. Ganesh Prasad Sah and Mrs. Iccha Ghale for their technical assistance at Kala-Azar Lab, B. P. Koirala Institute of Health Sciences.

\section{References}

[1] A. Mirjalili, E. Parmoor, B. S. Moradi, and B. Sarkari, "Microbial contamination of cell cultures: a 2 years study," Biologicals, vol. 33, no. 2, pp. 81-85, 2005.

[2] S. P. Langdon, "Cell culture contamination: an overview," Methods in Molecular Medicine, vol. 88, pp. 309-317, 2004.

[3] A. Vertut-Croquin, J. Bolard, M. Chabbert, and C. Gary-Bobo, "Differences in the interaction of the polyene antibiotic amphotericin B with cholesterol- or ergosterol-containing phospholipid vesicles. A circular dichroism and permeability study," Biochemistry, vol. 22, no. 12, pp. 2939-2944, 1983.

[4] L. J. Goad, G. G. Holz Jr., and D. H. Beach, "Sterols of Leishmania species. Implications for biosynthesis," Molecular and Biochemical Parasitology, vol. 10, no. 2, pp. 161-170, 1984.

[5] K. Sau, S. S. Mambula, E. Latz, P. Henneke, D. T. Golenbock, and S. M. Levitz, "The anti-fungal drug amphotericin B promotes inflammatory cytokine release by a Toll-like receptor- and CD14-dependent mechanism," Journal of Biological Chemistry, vol. 278, no. 39, pp. 37561-37568, 2003.

[6] M. B. Kurtz, C. Douglas, J. Marrinan et al., "Increased antifungal activity of L-733,560, a water-soluble, semisynthetic pneumocandin, is due to enhanced inhibition of cell wall synthesis," Antimicrobial Agents and Chemotherapy, vol. 38, no. 12 , pp. 2750-2757, 1994.

[7] D. J. Diekema, S. A. Messer, R. J. Hollis, R. N. Jones, and M. A. Pfaller, "Activities of caspofungin, itraconazole, posaconazole, ravuconazole, voriconazole, and amphotericin B against 448 recent clinical isolates of filamentous fungi," Journal of Clinical Microbiology, vol. 41, no. 8, pp. 3623-3626, 2003.

[8] L. R. Martinez, P. Ntiamoah, A. Casadevall, and J. D. Nosanchuk, "Caspofungin reduces the incidence of fungal contamination in cell culture," Mycopathologia, vol. 164, no. 6, pp. 279-286, 2007.

[9] R. L. Berens, R. Brun, and S. M. Krassner, "A simple monophasic medium for axenic culture of hemoflagellates," Journal of Parasitology, vol. 62, no. 3, pp. 360-365, 1976.

[10] N. Dabrowa, J. W. Landau, and V. D. Newcomer, "Generation time of Candida albicans in synchronized and nonsynchronized cultures," Medical Mycology, vol. 6, no. 1, pp. 51-56, 1968.

[11] D. M. Coder, "Assessment of cell viability," Current Protocols in Cytometry, Chapter 9, Unit 9.2, 2001.

[12] H. Motulsky and A. Christopoulos, Fitting Models to Biological Data using Linear and Nonlinear Regression, A Practical Guide to Curve Fitting, pp. 1-351, Oxford University Press, New York, NY, USA, 2004.
[13] T. R. Navin and R. D. Pearson, "Inhibition of Leishmania donovani growth by streptomycin and tobramycin," Annals of Tropical Medicine \& Parasitology, vol. 81, no. 6, pp. 731-733, 1987. 


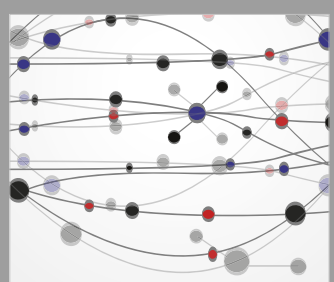

The Scientific World Journal
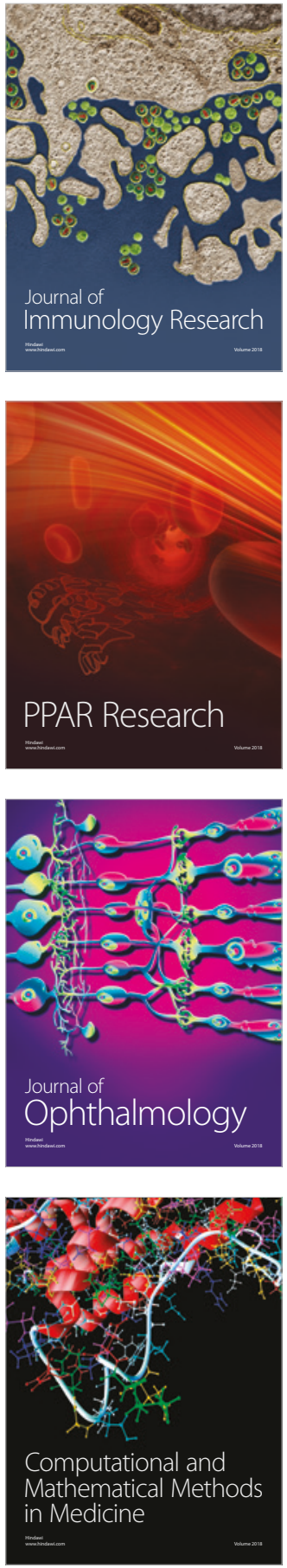

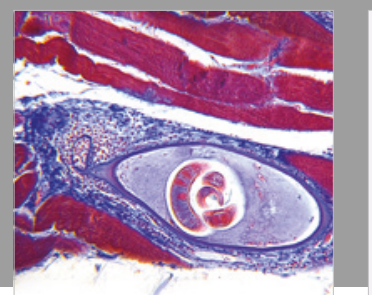

Gastroenterology Research and Practice

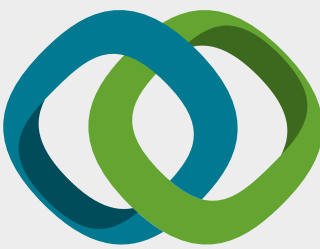

\section{Hindawi}

Submit your manuscripts at

www.hindawi.com
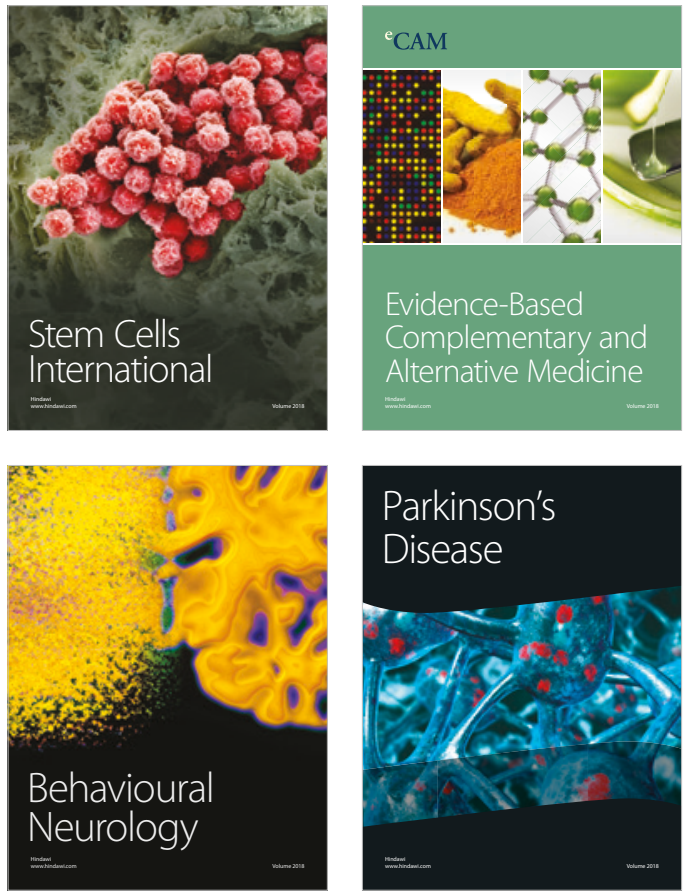

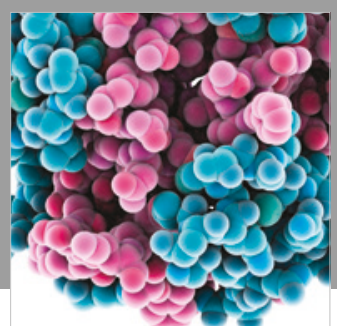

ournal of

Diabetes Research

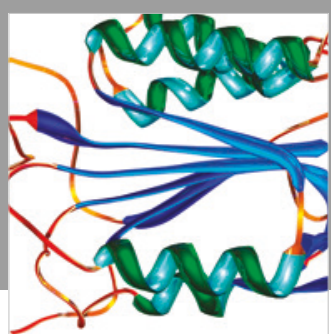

Disease Markers
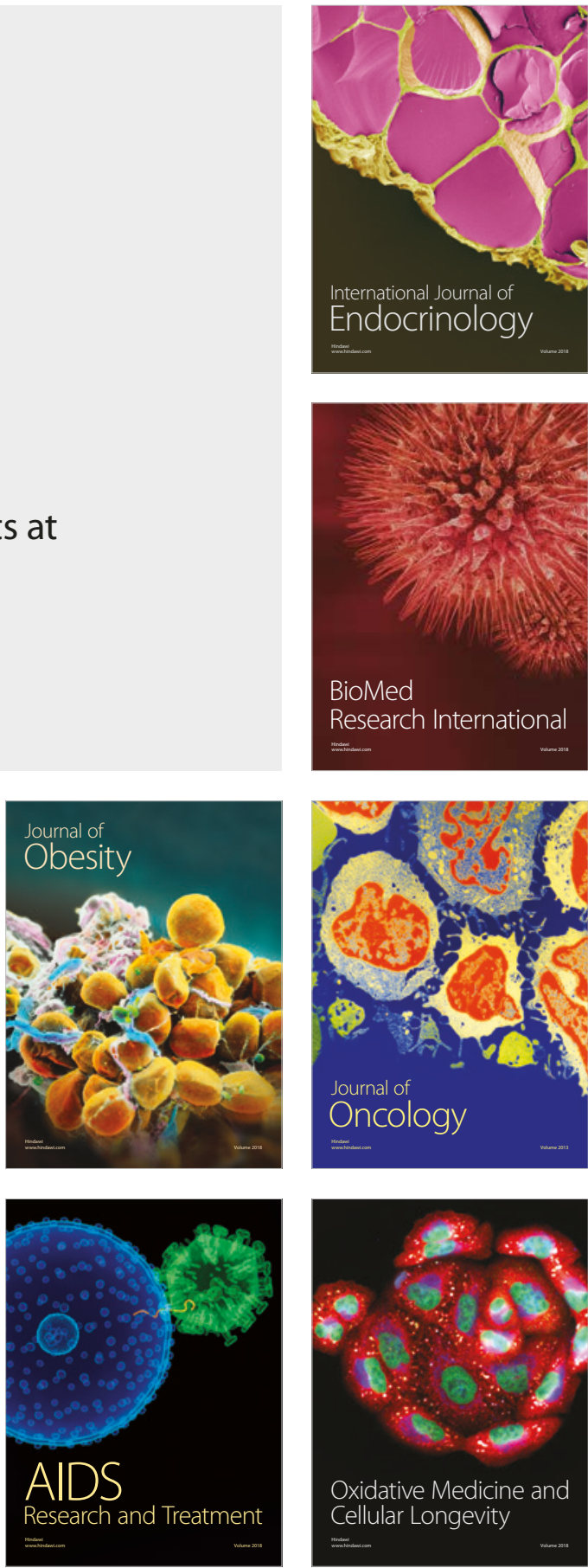